\title{
Gene expression of stem cells at different stages of ontological human development
}

\author{
Adolfo Allegra $^{\mathrm{a}, *}$, Roberta Altomare ${ }^{\mathrm{b}}$, Patrizia Curcio ${ }^{\mathrm{c}}$, Alessandra Santoro ${ }^{\mathrm{d}}$, \\ Attilio I. Lo Monte ${ }^{\mathrm{b}}$, Sergio Mazzola ${ }^{\mathrm{e}}$, Angelo Marino ${ }^{\mathrm{a}}$ \\ a ANDROS Day Surgery, Reproductive Medicine Unit, Palermo, Italy \\ ${ }^{\mathrm{b}}$ University of Palermo, Department of Oncological and Surgical Disciplines, Palermo, Italy \\ ' ANDROS Day Surgery, Fetal Medicine Unit, Palermo, Italy \\ ${ }^{\mathrm{d}}$ Villa Sofia-Cervello Hospital, Laboratory of Haematology, Palermo, Italy \\ e ANDROS Day Surgery, Medical Statistics Unit, Palermo, Italy
}

\section{A R T I C L E I N F O}

\section{Article history:}

Received 8 February 2013

Received in revised form 24 June 2013

Accepted 15 July 2013

\section{Keywords:}

Mesenchymal stem cells

Extra-embryonic tissues

Gene expression

\begin{abstract}
A B S T R A C T
Objectives: To compare multipotent mesenchymal stem cells (MSCs) obtained from chorionic villi (CV), amniotic fluid (AF) and placenta, with regard to their phenotype and gene expression, in order to understand if MSCs derived from different extra-embryonic tissues, at different stages of human ontological development, present distinct stemness characteristics.

Study design: MSCs obtained from 30 samples of CV, 30 of AF and 10 placentas (obtained from elective caesarean sections) were compared. MSCs at second confluence cultures were characterized by immunophenotypic analysis with flow cytometry using FACS CANTO II. The expression of the genes Oct4 (Octamer-binding transcription factor 4, also known as POU5F1), Sox-2 (SRY box-containing factor 2), Nanog, Rex-1 (Zfp-42) and Pax-6 (Paired Box Protein-6), was analyzed. Real-time quantitative PCR was performed by ABI Prism 7700, after RNA isolation and retro-transcription in cDNA. Statistical analysis was performed using non-parametric test Kruskal-Wallis (XLSTAT 2011) and confirmed by REST software, to estimate fold changes between samples. Each gene was defined differentially expressed if $p$ value was $<0.05$.

Results: Cells from all samples were negative for haematopoietic antigens CD45, CD34, CD117 and CD33 and positive for the typical MSCs antigens CD13, CD73 and CD90. Nevertheless, MSCs from AF and placentas showed different fluorescence intensity, reflecting the heterogeneity of these tissues. The gene expression of OCT-4, SOX-2, NANOG was not significantly different among the three groups. In AF, REX-1 and PAX-6 showed a higher expression in comparison to $\mathrm{CV}$.

Conclusions: MSCs of different extra-embryonic tissues showed no differences in immunophenotype when collected from second confluence cultures. The expression of OCT-4, NANOG and SOX-2 was not significantly different, demonstrating that all fetal sources are suitable for obtaining MSCs. These results open new possibilities for the clinical use of MSCs derived from easily accessible sources, in order to develop new protocols for clinical and experimental research.
\end{abstract}

(c) 2013 Elsevier Ireland Ltd. All rights reserved.

\section{Introduction}

Stem cells are primitive non-specialized cells, able to regenerate themselves and to differentiate into specific cell types [1]. Stem cells are classified as follows: totipotent, able to give rise to all cell types of the organism, including extra-embryonic tissues [2,3]; pluripotent, able to differentiate into cell types derived from the three germ layers but not into extra-embryonic tissues [4]; multipotent, capable of generating a limited number of cell types,

\footnotetext{
* Corresponding author. Tel.: +39 091 6785537; fax: +39 0916785522.

E-mail address: allegra@centroandros.it (A. Allegra).
}

restricted to a single germ layer [3]; unipotent, able to generate a single cell type. They are found in various adult tissues [5].

Stem cells can also be classified into embryonic (ESCs) and adult stem cells (ASCs) [6]. Both of these two cell types have some limitations: ESCs are pluripotent and have a high grade of selfrenewal [7] but may form tumours and develop host immune rejection [5]. Moreover, their use opens many ethical concerns. ASCs are multipotent and have a lower differentiation and proliferative potential than ESCs but do not present ethical problems [3,5].

To overcome these limitations, many efforts have been made to isolate stem cells from other sources [8]. On the one hand, patientspecific pluripotent stem cells from specialized adult cells have 
been obtained by nuclear reprogramming (induced pluripotent stem cells) [7]; on the other hand, multipotent stem cells have been isolated from the fetus but with high risk of morbidity, and from extra-embryonic tissues (fetal membranes, placenta and umbilical cord blood) [9]. Whereas umbilical cord blood is a source of haematopoietic stem cells, extra-embryonic tissues are utilized as an important source of stem cells with a high potential for differentiation. Among the different populations, multipotent mesenchymal stem cells (MSCs) represent a very promising tool in clinical applications for their differentiating potential towards mesoderm-derived lineage.

More than 120 clinical trials are in progress utilizing MSCs for different therapeutic applications [10,11]. In clinical practice, the main source of MSCs is adult bone marrow. The percentage of MSCs in the bone marrow, however, is very low $(0.001-0.01 \%)$, it decreases with age [12] and the retrieval techniques are dangerous. For these reasons it is important to find alternative sources of MSCs, such as extra-embryonic tissues [9] and adipose tissue, which offers a greater number of cells and is easily accessible [13,14].

Moreover, MSCs from extra-embryonic sources have intermediate characteristics between ESCs and ASCs [9,15]. In a recent study, MSCs obtained from 10 samples of chorionic villi showed multipotent properties in common with ESCs [16]. Although MSCs have well-known characteristics [17], their differences among different sources in terms of gene expression have not been determined yet [18]. It should be really interesting to understand if stem cell potential is reduced during human ontological development.

This topic has been previously explored [19] but the originality of our study derives from the contemporaneous analysis of the three different samples at different stages of human development. The rationale of this experimental study was to understand if MSCs derived from different extra-embryonic tissues, at different stages of human ontological development, presented different stemness potential.

We analyzed the expression of the stem cell master genes OCT-4 (Octamer-binding transcription factor 4, also known as POU5F1), SOX-2 (SRY box-containing factor 2) and NANOG in all samples. Moreover, we evaluated the expression of two other genes, REX-1 (Zfp-42) and PAX-6 (Paired Box Protein-6), expressed by stem cells under the control of Oct-4, Sox-2 and Nanog.

\section{Materials and methods}

In this experimental study, a comparison, in terms of phenotype and gene expression, among three different extraembryonic tissues - chorionic villi (CV), amniotic fluid (AF) and placenta was carried out.

$\mathrm{CV}$ and $\mathrm{AF}$ samples were obtained from 30 pregnant women for each group, aged 23-45 years, from the 11th to 14 th and the 15th to 21 st weeks respectively. The patients underwent chorionic villus sampling (CVS) and amniocentesis to look for chromosomal abnormalities. The great majority of the samples analyzed came from healthy pregnancies. Only 3 samples out of 60 (5\%) had a trisomy (trisomy 21). No difference in terms of immunophenotypic and gene expression analysis was found between the healthy pregnancies and those with chromosomal abnormalities. The placental samples were obtained from 10 pregnant women, aged 25-39 years and derived from elective caesarean sections, carried out around 38 weeks of gestation.

The study was approved by the local Ethics Committee ("Ethics Committee of ANDROS Day Surgery, Palermo, Approval date: November 15, 2010, Reference number 03/MR/10").

$\mathrm{CV}$ was first mechanically fragmented and then enzymatically digested using pronase (Merck) and collagenase (Sigma) for $15 \mathrm{~min}$ for both phases. Enzyme activity was arrested with Hank's Balanced Salts solution (Sigma). Cells were plated in non-coated $25 \mathrm{~cm}^{2}$ polystyrene culture flasks in Chang Medium (Irvine Scientific), a complete culture medium supplemented with penicillin, streptomycin, amphotericin, $10 \%$ fetal bovine serum (FBS) and glutamine (EuroClone).

AF samples, obtained from amniocentesis, were centrifuged at 1400 RPM for $10 \mathrm{~min}$. Cells were then plated in non-coated $25 \mathrm{~cm}^{2}$ polystyrene culture flasks in Chang Medium. All samples were collected in order to carry out prenatal diagnosis and were then used for the present study at the second passage of culture with the consent of each woman.

Placenta samples were first mechanically fragmented and then enzymatically digested using pronase (Merck) and collagenase (Sigma) for $30 \mathrm{~min}$ for each phase. Enzyme activity was arrested with culture media containing FBS, cells were counted and $5 \times 10^{5}$ cells were plated in non-coated $25 \mathrm{~cm}^{2}$ polystyrene culture flasks in Chang Medium (Irvine Scientific). These samples were also analyzed at the second passage of culture.

In order to confirm the fetal origin of the placenta samples, a 16 autosomal STR DNA genotyping (D3S1358, D19S433, D2S1338, D16S539, D18S51, TH01, D21S11, vWA, D8S1179, FGA, SE33, D22S1045, D10S1248, D1S1656, D12S391, D2S441), carried out using Powerplex 17 ESI System (Promega), was performed.

Flasks from all samples were stored at $37{ }^{\circ} \mathrm{C}$ in a $\mathrm{CO}_{2}$ incubator. Regarding placenta samples, non-adherent cells were removed and fresh medium was added after $48 \mathrm{~h}$. Culture medium was replaced twice a week in all samples and cells were replaced after reaching $80 \%$ (about every week) confluence using trypsine/EDTA (Sigma). MSCs were initially investigated for the spindle-shape morphology, absence of contamination by pathogens and for their proliferative potential in culture.

Cells from all samples were evaluated for cell surface antigens expression by flow cytometry, performed by FACS CANTO II (BD Bioscience). Four lasers evaluated simultaneously the physical parameters, Forward Scatter (FSC) and Side Scatter (SSC), and the expression of six different surface antigens on a single tube. Cells from all samples were collected at confluence, pelleted, suspended in $100 \mu \mathrm{l}$ of PBS at the concentration of $1 \times 10^{4}$ cells $/ \mu \mathrm{l}$ and stained with the antibodies. Cells were incubated in the dark for $15 \mathrm{~min}$ at room temperature. After incubation, cells were washed with PBS and suspended in $100 \mu \mathrm{l}$ of PBS to be analyzed with Facs Canto II.

Cells were incubated with the following antibodies: CD13-FITC (Dako), CD90-PE (Beckman Coulter), CD73-PE, CD34- PerCP-CY5.5, CD117- PE-CY7, CD33-APC and CD45-APC-CY7 (BD Biosciences).

Flow cytometer settings were established using unstained cells. Cells were gated by FSC to eliminate debris. A minimum of 10,000 events was counted for each analysis. Some samples were assayed by flow cytometry at different culture passages to determine any changes in surface molecule expression.

Cells in culture were treated with PBS and $2 \times$ RNA Nucleic Acid Purification Solution (Applied Biosystem) to lyse cells and preserve RNA. Total RNA was extracted by the platform ABI PRISM 6100 Nucleic Acid PrepStation (Applied Biosystem). The RNA concentration and purity were measured with a spectrophotometer by determining the absorbance ratio of $260 \mathrm{~nm}$ to $280 \mathrm{~nm}(>1.8)$. To assess the integrity, RNA fragments were resolved on a $1.2 \%$ agarose gel looking for subunits18S and 28S of rRNA. $1 \mu \mathrm{g}$ of total RNA was then reverse-transcribed with High-Capacity cDNA Archive kit (Applied Biosystem). The reaction was performed in a thermocycler in a final volume of $12 \mu \mathrm{l}\left(10 \mathrm{~min}\right.$ at $25^{\circ} \mathrm{C}, 60 \mathrm{~min}$ at $37{ }^{\circ} \mathrm{C}$ and $7 \mathrm{~min}$ at $4{ }^{\circ} \mathrm{C}$ ).

Real-time quantitative PCR was conducted on a ABI Prism 7700 (Applied Biosystem). $2.5 \mu$ l of cDNA were added with the PCR master mix (Applied Biosystem) and the specific primers and probes (TaqMan Gene Expression Assay, Applied Biosystem). The 
Table 1

Characteristics of the samples.

\begin{tabular}{lll}
\hline Samples & $\begin{array}{l}\text { Patients' age } \\
\text { (mean } \pm \text { standard } \\
\text { deviation) }\end{array}$ & $\begin{array}{l}\text { Gestational age } \\
\text { (mean } \pm \text { standard } \\
\text { deviation) }\end{array}$ \\
\hline Chorionic villi $(n=30)$ & $36.3 \pm 4.9$ & $12.5 \pm 0.8$ \\
Amniotic fluid $(N=30)$ & $36.9 \pm 4.1$ & $17.3 \pm 1.8$ \\
Placentas $(n=10)$ & $32.4 \pm 4.7$ & $38.2 \pm 0.3$ \\
\hline
\end{tabular}

specificity of qPCR products was guaranteed by Applied Biosystem, which checks the specificity of primers and probes.

Each sample of cDNA from different cell lines (CV, AF and placentas) was amplified for the housekeeping gene GAPDH (code hs99999905_m1) as relative gene and for genes OCT-4 (code hs01895061_u1), SOX-2 (code hs01053049_s1), NANOG (code hs02387400_g1), REX-1 (code hs01938187_s1) and PAX-6 (code hs01088112_m1). For the elaboration of data, a relative quantification by calculating the difference between the target gene and the control gene $\mathrm{Ct}$ was carried out. Reaction mix with water instead of cDNA was used as negative control. The thermal protocol used was: $10 \mathrm{~min}$ at $37^{\circ} \mathrm{C}, 2 \mathrm{~min}$ at $50{ }^{\circ} \mathrm{C}$ and $10 \mathrm{~min}$ at $95^{\circ} \mathrm{C}$ for 50 holds, $5 \mathrm{~s}$ at $95{ }^{\circ} \mathrm{C}$ and $60{ }^{\circ} \mathrm{C}$ forever.

Concerning statistical analysis, data from real-time quantitative PCR were analyzed by the non-parametric Kruskal-Wallis test using the software XLSTAT and then validated by the Relative Expression Software Tool (REST), to estimate fold changes among samples. Each gene was defined with a different expression when estimated $p$-value was $<0.05$. To increase the stability of the results, we applied filtering criteria that included mRNA, which were reliably quantifiable (cut off $<30 \mathrm{Ct}$ for the housekeeping gene). Undetermined values of $\mathrm{Ct}$ were estimated as $50 \mathrm{Ct}$ (the last cycle of the reactions).

\section{Results}

Thirty samples of CV and 30 samples of AF were obtained for this study at the end of the second passage of culture and they were tested after reaching the second confluence. Ten placenta samples were isolated from the fresh tissue and they were maintained in culture up to the second confluence in order to remove differences among samples.

Table 1 indicates the mean age of the patients and the mean week of sampling for each group. Four samples from all sources were maintained in culture for over a month to evaluate the behaviour of these cells. We observed that cells from different fetal sources are easy to expand in vitro and show a fibroblast-like morphology, consistent with that of typical MSCs.

Fetal stem cells from all samples were firstly characterized by flow cytometry for the expression of 7 cell surface antigens (CD13, CD90, CD73, CD34, CD117, CD33 and CD45) in order to better characterize MSCs.

MSCs from CV, AF and placentas were clearly negative for the expression of the haematopoietic surface antigens CD34, CD117, CD33 and CD45, while they expressed the typical MSCs antigens CD13, CD73 and CD90 at high fluorescence intensity (Fig. 1, boxes A, B, and C) [20]. Some samples of AF showed a specific cell population which expressed the MSCs markers CD73 and CD90 at different fluorescence intensities (Fig. 1, box D). Furthermore, the same heterogeneity was found for the placenta samples.
A

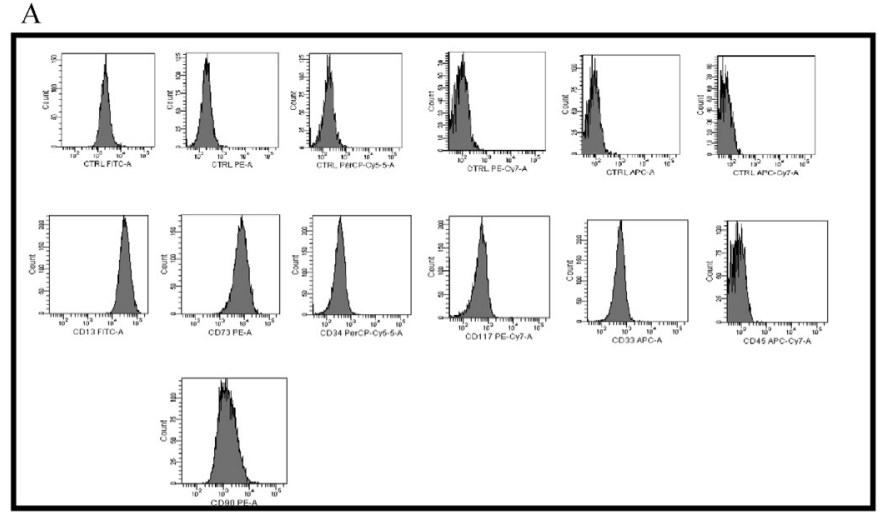

B

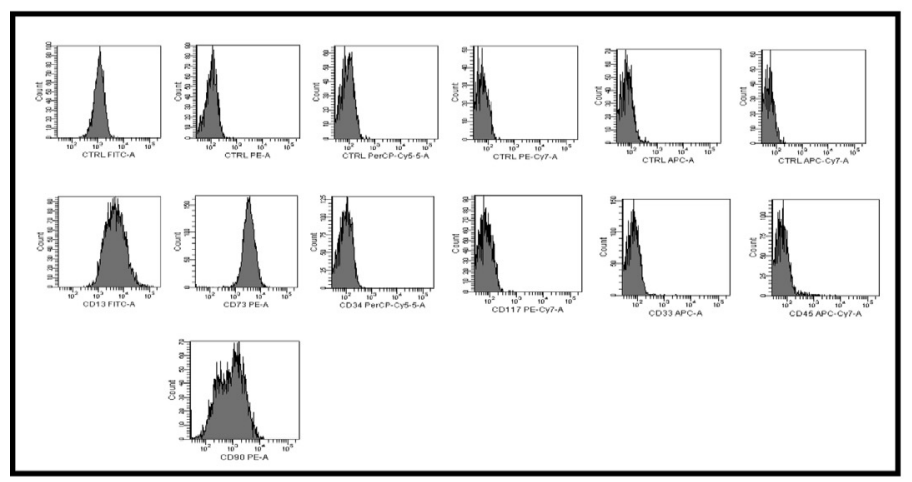

$\mathrm{C}$

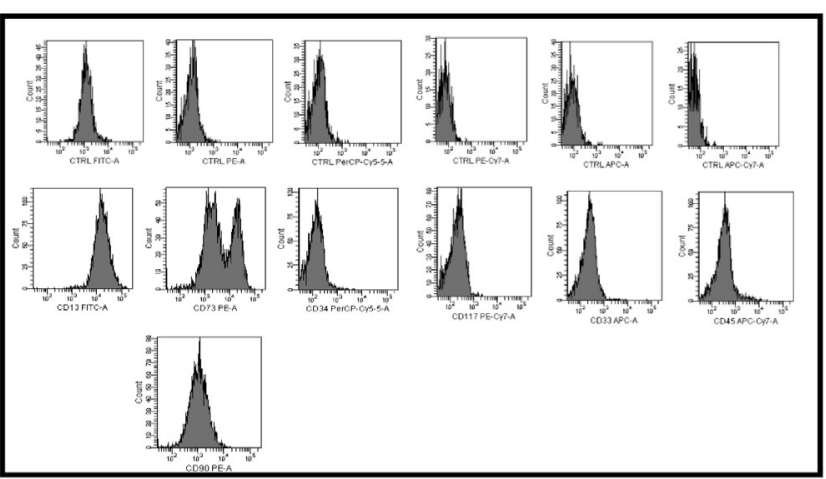

$\mathrm{D}$

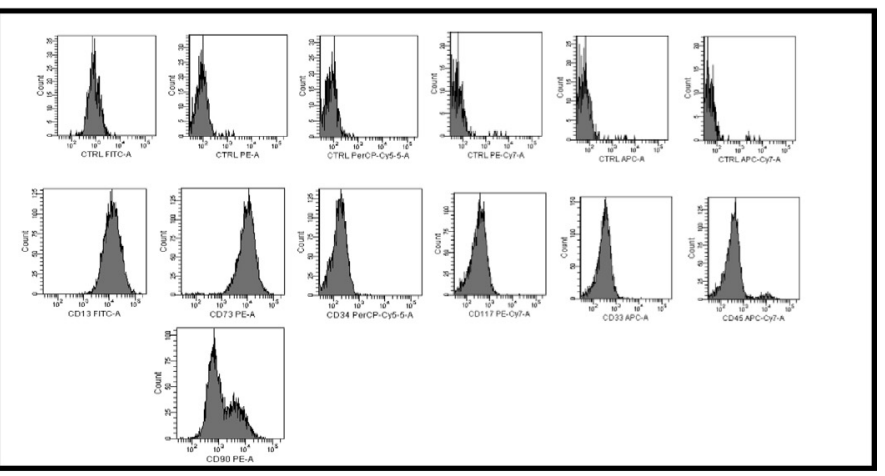

Fig. 1. Flow cytometry analysis of mesenchymal stem cells from extra-embryonic tissues. Cells were investigated for the expression of haematopoietic antigens CD34, CD117, CD33 and CD45 and mesenchymal antigens CD13, CD90 and CD73. Boxes A, B, and C represent a sample of each specific tissue (box A for CV, box B for AF and box C for placentas). Box D is an example of AF sample which expresses the MSC markers CD73 and CD90 at a different fluorescence intensity. 
Table 2

Mean ( \pm SEM) $\Delta$ Ct values of chorionic villi, amniotic fluid and placentas. A lower $\Delta$ Ct indicates a higher expression of the specific gene.

\begin{tabular}{|c|c|c|c|c|c|}
\hline Samples & SOX-2 & OCT-4 & NANOG & REX-1 & PAX-6 \\
\hline Chorionic villi $(n=29)$ & $12.46 \pm 3.34$ & $10.58 \pm 1.47$ & $11.23 \pm 2.42$ & $16.38 \pm 2.68$ & $19.85 \pm 2.77$ \\
\hline Amniotic fluid $(n=27)$ & $11.26 \pm 2.84$ & $10.61 \pm 2.13$ & $11.27 \pm 2.89$ & $12.9 \pm 0.72$ & $14.45 \pm 3.45$ \\
\hline Placentas $(n=6)$ & $11.69 \pm 2.68$ & $8.6 \pm 1.69$ & $11 \pm 1.45$ & $14.82 \pm 2.48$ & $15.86 \pm 1.10$ \\
\hline
\end{tabular}

No differences were found in analyzed samples at different passages of culture, indicating that MSCs phenotypic characteristics are not lost during different phases of cultures (data not shown).

Real-time PCR was performed on 30 CV samples, 30 AF samples and 10 placenta samples at the end of the second confluence. The expression of the five genes investigated, OCT-4, SOX-2, NANOG, $R E X-1$ and $P A X-6$, was related to the expression of the housekeeping gene GAPDH which indicates the success of cDNA synthesis. Some samples were discarded for statistical analysis because of the poor quality of the real-time PCR data. As a result of these limitations, 29 samples of CV, 27 samples of AF and 6 samples of placenta were used for gene expression analysis.

We estimated the $\Delta \mathrm{Ct}$ as the difference between $\mathrm{Ct}$ of each target gene and $\mathrm{Ct}$ of GAPDH, as control gene. A lower $\Delta \mathrm{Ct}$ indicates a higher expression of the gene and a higher $\Delta \mathrm{Ct}$ indicates a lower expression of the gene. The expression of the five genes analyzed was quite heterogeneous among samples within the same fetal source. Table 2 summarizes the mean $\Delta \mathrm{Ct}$ values of the three sources obtained from real-time PCR.

The Kruskal-Wallis test showed that there were no significant differences in terms of gene expression among all MSCs for the master genes OCT-4 $(p$-value $=0.15)$, SOX-2 $(p$-value $=0.32)$ and NANOG ( $p$-value $=0.89$ ), whereas REX-1 and PAX-6 genes were found to be differently expressed among $\mathrm{CV}, \mathrm{AF}$ and placenta samples in terms of median with statistical significance ( $p$ value $=0.04$ for $P A X-6$ and $p$-value $=0.02$ for $R E X-1$ ) .

Comparisons among groups were conducted by the software REST. Graphical output of the results is presented in the box plots
(Fig. 2). In order to interpret these, it is important to keep in mind that a greater asymmetry in the position of the box in respect to the whiskers represents a greater difference in gene expression. Expression of genes REX-1 and PAX-6 was found significantly higher in AF samples ( $p=0.004$ for $R E X-1$ and $p=0.0001$ for $P A X-6$ ) compared with $\mathrm{CV}$ samples (substantial negative asymmetry). Expression of REX-1 and PAX-6 was higher in AF compared with placenta samples (slight negative asymmetry) and lower in CV samples compared with the placenta samples (slight positive asymmetry). In both cases these differences did not achieve significance $(p$-value $=0.081$ for $R E X-1$ and $p$-value $=0.414$ for $P A X$ 6 for AF vs placenta; $p$-value $=0.641$ for $R E X-1$ and $p$-value $=0.123$ for $P A X-6$, for CV vs placenta).

Moreover, no significant changes in gene expression profile were observed by maintaining some samples in culture for over a month (Fig. 3).

\section{Comments}

As far as we know, this paper represents the first comparison among MSCs derived from different extra-embryonic tissues at different stages of human development. These MSCs showed no differences in morphology and growth characteristics when maintained in culture under the same conditions.

Some samples of AF and placenta showed a heterogeneous phenotype as demonstrated by flow cytometry in which AF and placenta samples expressed CD73 and CD90 at different fluorescence intensity.

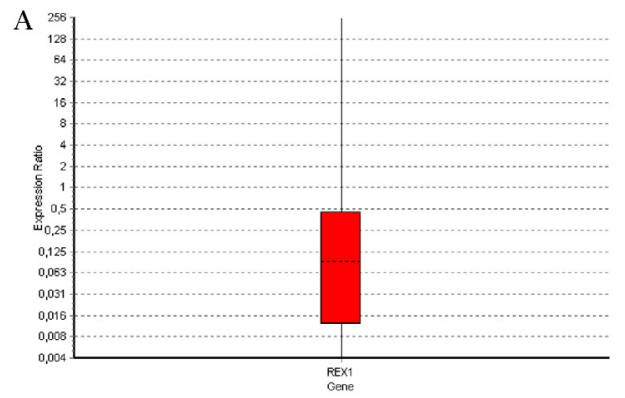

\begin{tabular}{|l|l|c|c|c|c|c|}
\hline Gene & Type & Reaction Efficiency & Expression & Std. Error & $\mathbf{9 5 \%}$ C.I. & P \\
\hline GAPDH & Reference & 1,0 & 1,000 & & & \\
\hline REXI & Target & 1,0 & 0,113 & $0,006-0,901$ & $0,001-1.153,162$ & 0,004 \\
\hline
\end{tabular}

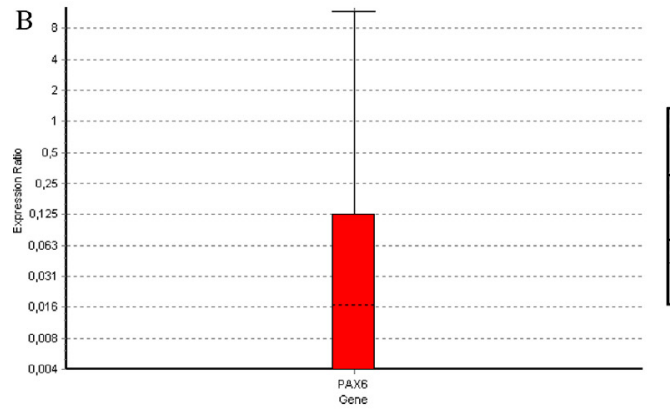

\begin{tabular}{|l|l|c|c|c|c|c|}
\hline Gene & Type & Reaction Efficiency & Expression & Std. Error & $\mathbf{9 5 \%}$ C.I. & P \\
\hline GAPDH & Reference & 1,0 & 1,000 & & & \\
\hline PAX6 & Target & 1,0 & 0,016 & $0,001-0,413$ & $0,000-4,739$ & 0,0001 \\
\hline
\end{tabular}

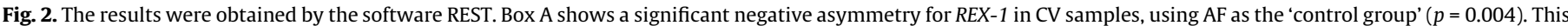

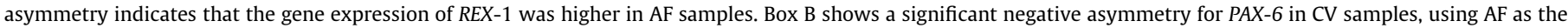
'control group' ( $p=0.0001$ ). This negative asymmetry indicates a higher expression of $P A X-6$ in $A F$ samples. 

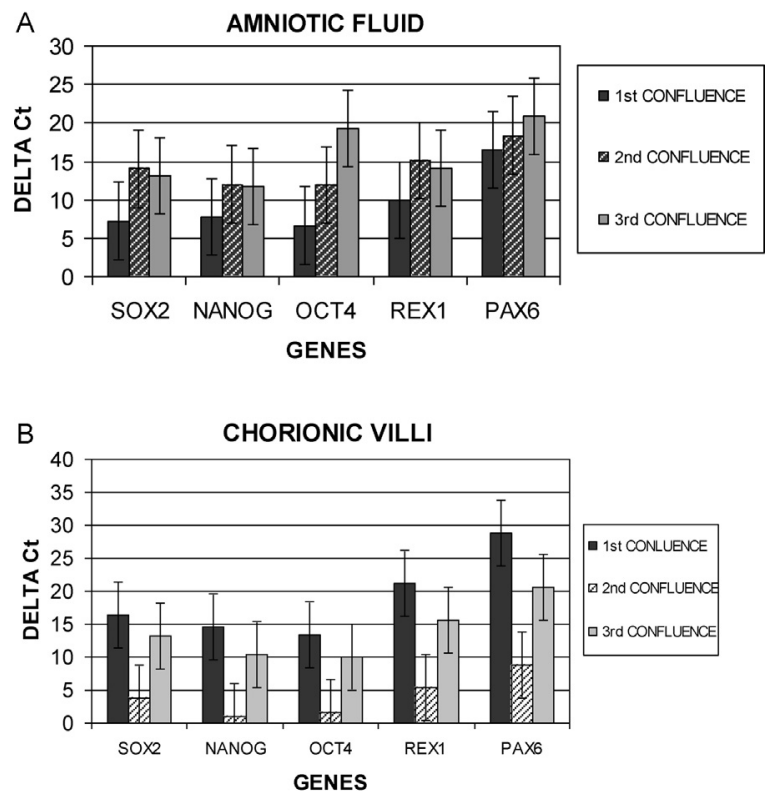

Fig. 3. Gene expression profile of a sample of $A F(A)$ and a sample of $C V(B)$ maintained in culture for over a month. $\Delta \mathrm{Ct}$ was estimated as the difference between each target gene $\mathrm{Ct}$ and GAPDH Ct. No significant difference was observed for gene expression profile.

This observation reflects the heterogeneity of the tissue of origin [21], consisting of multiple cell types derived from fetal and maternal tissues [22,23]. In particular, AF cells derive from both extra-embryonic and embryonic tissues [24]. The general consensus is that AF cells mainly consist of fetal cells shed in the amniotic cavity from the developing skin, respiratory apparatus, urinary and gastrointestinal tracts [25].

Cells from all samples were analyzed for the expression of OCT4, SOX-2, NANOG, REX-1 and PAX-6 genes, which are important for the maintenance of stem potential [26,27]. The differences in expression of OCT -4, SOX-2 and NANOG genes were not significant, demonstrating that all fetal sources are equally suitable for obtaining MSCs.

An up-regulation was found for REX-1 and PAX-6 genes in the AF compared to $\mathrm{CV}$.

$R E X-1$ is a gene expressed in ESCs and its expression appears to be regulated by Oct- 4 , Sox- 2 and Nanog. Rex- 1 is a marker for a subpopulation of undifferentiated embryonic cells [28] and acts to reduce differentiation in ESCs [29]. Furthermore, $R E X-1$ expression in mice decreases at the beginning of differentiation, during the embryo development [30]. The higher significant expression of this gene in AF samples could be related to the capacity of limiting the differentiation of MSCs. In the period of ontological development in which amniocentesis is carried out, the differentiation process is progressively reducing and this phenomenon could explain the significant higher expression of REX-1 in AF $(p=0.004)$ in comparison with $\mathrm{CV}$. On the other hand, during the period at which CVS is performed, the differentiation process is entirely active and $R E X-1$ expression is consequently low. REX-1 expression is also higher in placentas compared with $\mathrm{CV}$, though without statistical significance.

$P A X-6$ is a master gene involved in ectodermal differentiation, particularly in the development of the eye [31]. The development of the eye temporally coincides with the amniocentesis and this could be the reason of its higher expression in AF samples. The temporally limited expression of $P A X-6$ is also, indirectly, demonstrated by the fact that placenta samples show lower expression of this gene, with a trend towards the statistical significance, in comparison to $\mathrm{AF}$ (Table 2). We believe that PAX-6 expression is not enhanced in placenta as the eye has already developed.

Thus, the evidence of a higher expression in AF of REX-1 and $P A X-6$ may be correlated to a more advanced gestational age, in which these genes are activated.

The non-significance of the three master genes (OCT-4, SOX-2 and $N A N O G$ ), among the different tissues, is an unexpected result. This finding, however, is important experimental knowledge which can allow the clinical use of those MSCs derived from the simplest achievable source, which could be the placenta, as this is a discarded tissue.

Our experimental results need to be confirmed and validated in larger studies but we believe that the field of MSCs obtained from extra-embryonic tissues should be expanded for future possible applications in regenerative medicine.

\section{References}

[1] Zipori D. The stem state: plasticity is essential, whereas self-renewal and hierarchy are optional. Stem Cells 2005;23:719-26.

[2] Dominici M, Le Blanc K, Mueller I, et al. Minimal criteria for defining multipotent mesenchymal stromal cells. The International Society for Cellular Therapy position statement. Cytotherapy 2006;8:315-7.

[3] Mitalipov S, Wolf D. Totipotency, pliuripotency and nuclear reprogramming. Adv Biochem Eng Biotechnol 2009:114:185-99.

[4] Leeb C, Jurga M, McGuckin C, et al. New perspectives in stem cell research: beyond embryonic stem cells. Cell Prolif 2011;44:9-14.

[5] Rao MS. Stem sense: a proposal for the classification of stem cells. Stem Cells Dev 2004;13:452-5.

[6] Thomson JA, Itskovitz-Eldor J, Shapiro SS, et al. Embryonic stem cell lines derived from human blastocyst. Science 1998;282:1145-7.

[7] Takahashi K, Yamanaka S. Induction of pluripotent stem cells from mouse embryonic and adult fibroblast cultures by defined factors. Cell 2006;126: $663-76$.

[8] Amabile G, Meissner A. Induced pluripotent stem cells: current progress and potential for regenerative medicine. Trends Mol Med 2009;15:59-68.

[9] Pojda Z, Machaj EK, Oldak T, Gajkowska A, Jastrzewska M. Non hematopoietic stem cells of fetal origin-how much of today's enthusiasm will pass the time test? Folia Histochem Cytobiol 2005;43:209-12.

[10] Ma T. Mesenchymal stem cells: from bench to beside. World J Stem Cells 2010;2:13-7.

[11] Trounson A, Thakar RG, Lomax G, Gibbons D. Clinical trials for stem cell therapies. BMC Med 2011;10(9):52.

[12] Mihu CM, Mihu D, Costin N, Rus Ciuca D, Susman S, Ciortea R. Isolation and characterization of stem cells from the placenta and the umbilical cord. Rom J Morphol Embryol 2008;49:441-6.

[13] Kern S, Eichler H, Stoeve J, Kluter H, Bieback K. Comparative analysis of mesenchymal stem cells from bone marrow, umbilical cord blood, or adipose tissue. Stem Cells 2006;24:1294-301.

[14] Rastegar F, Shenaq D, Huang J, et al. Mesenchymal stem cells: Molecular characteristics and clinical applications. World J Stem Cells 2010;2: 67-80.

[15] Bieback K, Brinkmann I. Mesenchymal stromal cells from human perinatal tissues: from biology to cell therapy. World J Stem Cells 2010;2:81-92.

[16] Katsiani E, Garas A, Skentou C, Tsezou A, Dafopoulos K, Messinis IE. Chorionic villi derived mesenchymal stem cells and expression of embryonic stem cells markers. Hum Reprod 2012;27(Suppl. 1). O-0065.

[17] Kim J, Lee Y, Kim H, et al. Human amniotic fluid-derived stem cells have characteristics of multipotent stem cells. Cell Prolif 2007;40:75-90.

[18] Hass R, Kasper C, Bohm S, Jacobs R. Different populations and sources of human mesenchymal stem cells (MSC): A comparison of adult and neonatal tissue-derived MSC. Cell Commun Signal 2011;9:12.

[19] Jones GN, Moschidou D, Puga-Iglesias TI, et al. Ontological differences in first compared to third trimester human fetal placental chorionic stem cells. PLoS One 2012;7:e43395

[20] Tarnok A, Ulrich H, Bocsi J. Phenotypes of stem cells from diverse origin. Cytometry 2010;77:6-10.

[21] Poloni A, Rosini V, Mondini E, et al. Characterization and expansion of mesenchymal progenitor cells from first-trimester chorionic villi of human Placenta. Cytotherapy 2008;10:690-7.

[22] In't Anker PS, Scherjon SA, Kleijburg-Van Der Keur C, et al. Isolation of mesenchymal stem cells of fetal or maternal origin from human placenta. Stem Cells 2004;22:1338-45.

[23] Cananzi M, Atala A, De Coppi P. Stem cells derived from amniotic fluid: new potentials in regenerative medicine. Berlin Conference contribution. Reprod Biomed Online 2009;18:17-27.

[24] Gosden CM. Amniotic fluid cell types and culture. Br Med Bull 1983;39: 348-54.

[25] Fauza D. Amniotic fluid and placental stem cells. Best Pract Res Clin Obstet Gynaecol 2004;18:877-91. 
[26] Guillot PV, Gotherstrom C, Chan J, Kurata H, Fisk NM. Human first-trimester fetal MSC express pluripotency markers and grow faster and have longer telomeres than adult MSC. Stem Cells 2007;25:646-54.

[27] Poloni A, Rosini V, Mondini E, et al. Characterization and expansion of mesenchymal progenitor cells from first-trimester chorionic villi of human placenta. Cytotherapy 2008;10:690-7.

[28] Bacenková D, Rosocha J, Tóthová T, Rosocha L, Šarisský M. Isolation and basic characterization of human term amnion and chorion mesenchymal stromal cells. Cytotherapy 2011;13:1047-56.
[29] Scotland KB, Che S, Sylvester R, Gudas LJ. Analysis of Rex-1 (zfp42) function in embryonic stem cell differentiation. Dev Dyn 2009;238:1863-77.

[30] Rogers MB, Hosler BA, Gudas LJ. Specific expression of a retinoic acid-regulated, zinc-finger gene, Rex-1, in preimplantation embryos, trophoblast and spermatocytes. Development 1991;113:815-24.

[31] Smith AN, Miller LA, Radice G, Padan R, Lang RA. Stage-dependent modes of Pax-6-Sox-2 epistasis regulate lens development and eye morphogenesis. Development 2009;136:2977-85 